\title{
River-bed erosion due to changing boundary conditions: performance of a protective measure
}

\author{
DONATELLA TERMINI \\ Dipartimento di Ingegneria Civile, Ambientale, Aerospaziale, dei Materiali, Viale delle Scienze, University of Palermo, \\ Italy \\ donatella.termini@unipa.it
}

\begin{abstract}
Due to the introduction of man-made sediment barriers along a river, the amount of sediment load entering the downstream river reach is different to that leaving the reach, and erosion processes occur downstream of the barrier itself. Designers are often required to take into account the scouring process and to include adequate protective measures against the local scour. This paper addresses the performance of bio-engineering protective measures against the erosion process. In particular, a green carpet, realized with real flexible vegetation, has been used as the protective measure against erosion processes downstream of a rigid bed. Analyses are based on experimental work carried out in a straight channel constructed at the laboratory of the Dipartimento di Ingegneria Civile, Ambientale, Aereospaziale, dei Materiali, Palermo University (Italy).
\end{abstract}

Key words rivers; local scouring; flow characteristics; protective measure; vegetation

\section{INTRODUCTION}

Designers are often required to take into account the scouring process around structural interventions and to include adequate protective measures against the local scour. The design of the protective measures, in turn, needs knowledge of the flow velocity field and of geometric characteristics of scour transient profiles.

Most studies have been devoted to formulation of empirical equations to estimate the maximum (or equilibrium) scour depth and length (among others Breusers et al. 1977, Lenzi et al. 2002, Marion et al. 2006) for a specific scour problem. This information is important to identify adequate protective measures against scouring processes. However, to evaluate the advantages of a specific protective technique, it is important to investigate the effects of the technique itself on the flow velocity field and sediment transport processes.

Vegetation has recently been used as a bioengineering technique against erosion. In an attempt to respond to the aforementioned question, an experimental programme has been conducted, at the Dipartimento di Ingegneria Civile, Ambientale, Aereospaziale, dei Materiali (DICAM) - Palermo University (Italy), to analyse scour caused by a horizontal jet downstream of a rigid bed. The experiments were conducted to examine the flow velocity field, including turbulent characteristics, within the scour hole. This analysis is fundamental to correctly simulate the bed-load transport and the temporal evolution of the scour hole and to define protective measures to reduce scouring. Some of the results on flow velocity and turbulence fields inside the scour hole were discussed in detail in previous work (Termini and Sammartano 2012). In this paper, attention is paid to the effects caused by vegetation used as a protective measure against the development of the scour hole downstream of the rigid bed.

Analyses are based on experimental work carried out in a straight channel, with and/without the protective vegetated bed, constructed at the laboratory of the DICAM. Detailed measures of flow velocity field inside the scour hole have been obtained through both a 2-D LDA anemometer and an acoustic velocimeter profiler (DOP 2000).

\section{EXPERIMENTAL APPARATUS}

The experiments were carried out in a rectangular straight flume, $11.2 \mathrm{~m}$ long and $0.4 \mathrm{~m}$ wide. In the first reach of the channel $(2.65 \mathrm{~m}$ long $)$ the bed was rigid and in the remaining part $(8.55 \mathrm{~m}$ long) the bed was mobile. The bed was of quartz sand (median sediment diameter $D_{50}=0.86 \mathrm{~mm}$ and geometric standard deviation $\sigma_{g}=1.61 \mathrm{~mm}$ ), with a longitudinal slope equal to $0.4 \%$. The experimental apparatus is shown in Fig. 1. 


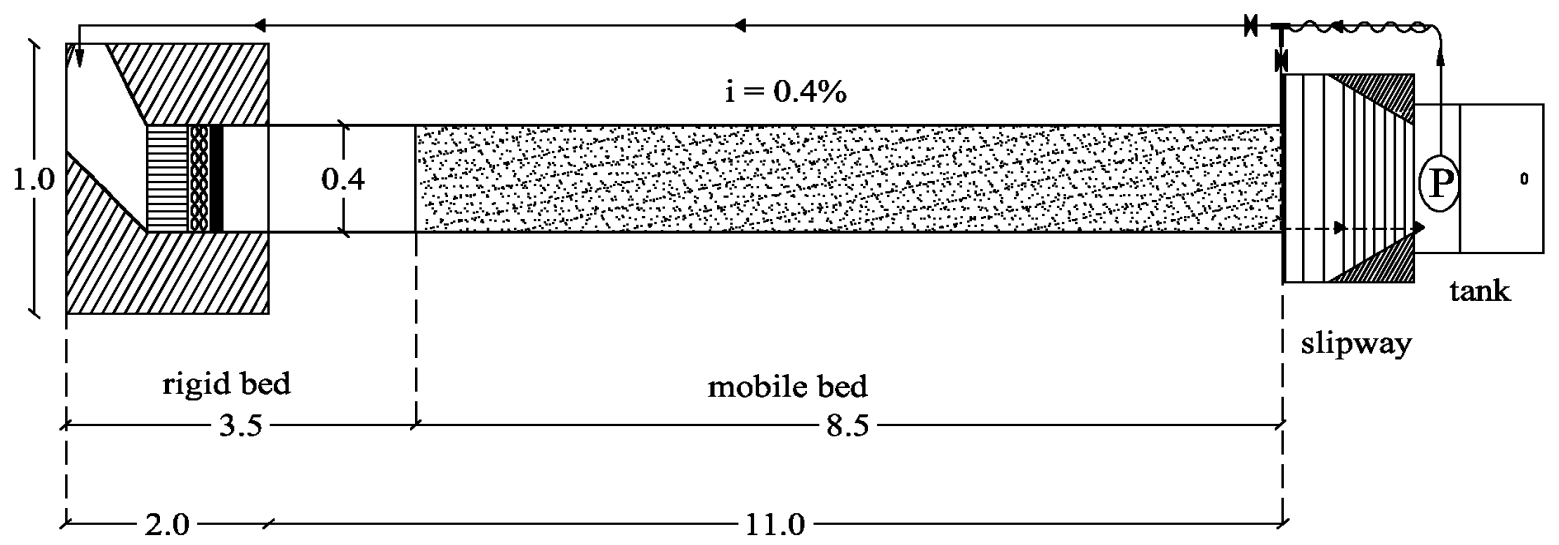

Fig. 1 Plane view of the experimental apparatus

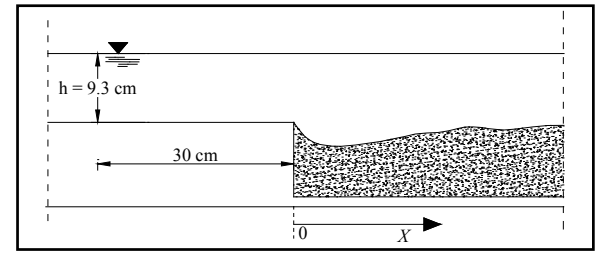

(a)

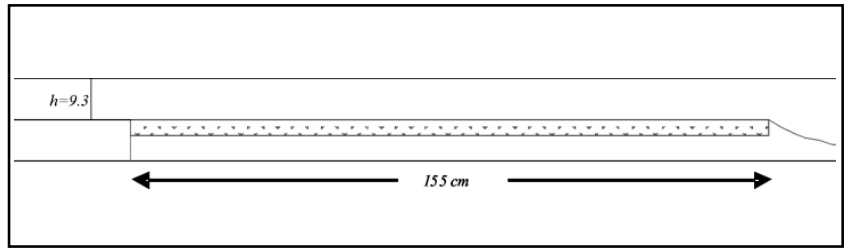

(b)

Fig. 2 Schematic view of channel bed: (a) NV run; (b) WV run.

Two runs were carried out with water discharge $Q=35 \mathrm{~L} / \mathrm{s}$ (which allowed a water depth over the rigid-bed reach of $h=9.3 \mathrm{~cm}$ to be obtained, see Fig. 2). Hereafter, the downstream section of the rigid-bed channel reach is denoted as initial section $(X=0$, as in Fig. 2). The first run (hereafter called NV run) was conducted to analyse the evolution of a scour hole downstream of the rigidbed channel reach and to measure the flow velocity components inside the scour hole (Fig. 2(a)). Then, the bed of a channel reach ( $1.55 \mathrm{~m}$ long) downstream of the rigid-bed was covered with real herbaceous (flexible) vegetation (Fig. 2(b)) and a second run (the WV run) was carried out.

During the NV run the longitudinal and vertical velocity components were measured using a two-dimensional laser anemometer, LDA2D by Dantec s.r.1.; the transverse component was measured using an ultrasonic anemometer, DOP2000 by Signal Processing s.a. The measures were performed in sections $5 \mathrm{~cm}$ distant from each other (starting from the initial section) along the mobile-bed channel reach. Details of the experimental conditions of the NV run can be found in Termini and Sammartano (2010, 2012).

During WV run the velocity components (longitudinal, vertical and transversal) were measured using the DOP2000. The measures were performed in sections 1-5 as reported in Fig. 3, which are $40 \mathrm{~cm}$ or so distant from each other. For the analyses described in the present work, only sections $1-3$ have been considered.

The measured data have been analysed by assuming an orthogonal reference system having origin in the initial section, at the intersection between the horizontal plane including the bed profile and the right bank (see Fig. 3).

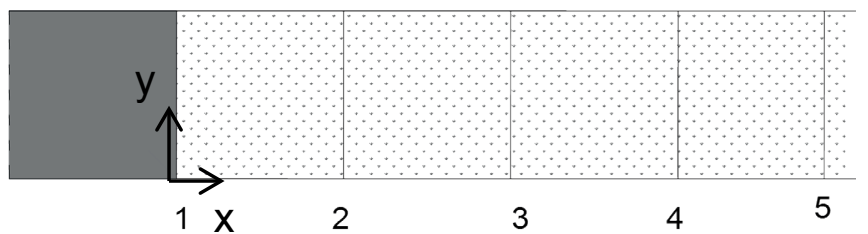

Fig. 3 Measurement sections - WV run. 


\section{EXPERIMENTAL RESULTS}

The time series of the flow velocity components measured at each measurement point during both runs have been used to determine the corresponding time-averaged velocity components, $U, V$ and $W(U=$ longitudinal component, $V=$ transversal component, $W=$ vertical component $)$.

More detailed analyses of scouring evolution and flow velocity field determined during the NV run can be found in Termini and Sammartano (2010, 2012). Thus here only some particular results, which are fundamental for the comparison, are reported. From the analysis of measured bed level data it was determined that the channel reach affected by scouring phenomena has a total length, $L_{T O T}$, of $50 \mathrm{~cm}$. Two scour holes were located almost symmetrically with respect to the channel axis and the maximum scour depth occurred at a distance $X$ from the initial section ranging from $0.3 L_{T O T}$ and $0.4 L_{T O T}$, in agreement with other experimental studies (Gaudio and Marion 2003). Figure 4 reports the bed profile and the vector plot of the resultant longitudinal velocity, $U_{l}$ (of intensity $U_{1}=\sqrt{U^{2}+W^{2}}$ ) in the longitudinal plane (parallel to flow direction) at $Y$ $=4 \mathrm{~cm}$. It can be observed from this figure that the maximum excavation occurs at $5<X<15$. Inside this $X$-range, low values of $U_{l}$ are found near the bed within the scour hole. For $X>10$, the region of low values of $U_{l}$ gradually increases towards the free surface, extending to the whole water depth. Erosion occurs where the longitudinal gradient of $U_{l}$ increases. Within the scour hole (where the maximum excavation occurs), small negative values of the longitudinal velocity occur

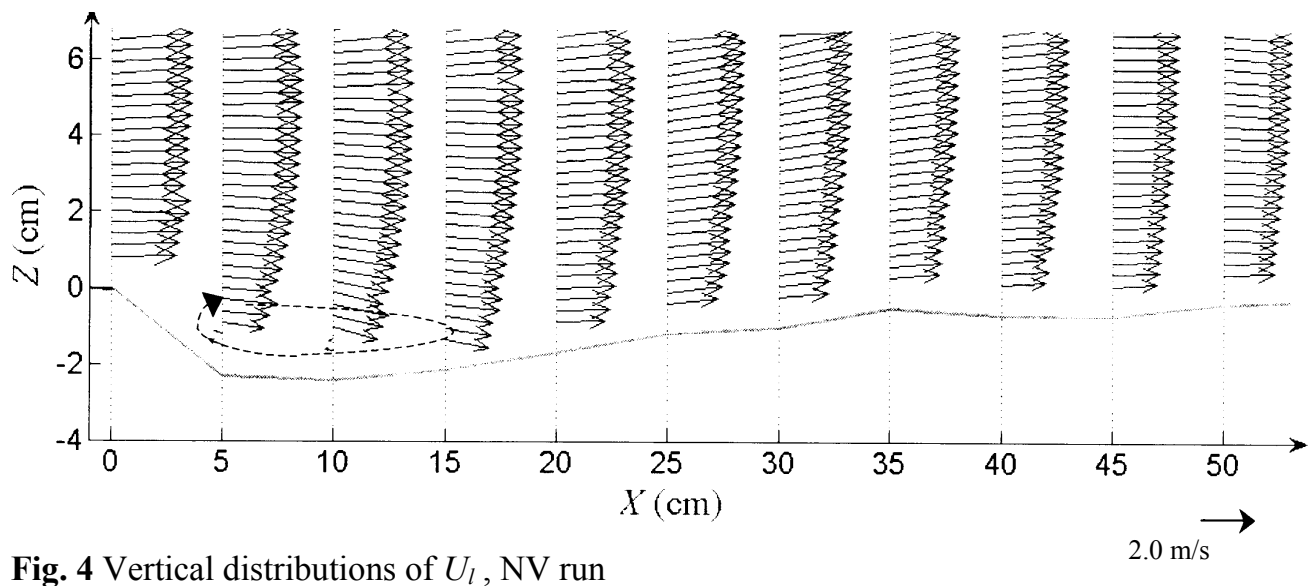

Fig. 4 Vertical distributions of $U_{l}$, NV run
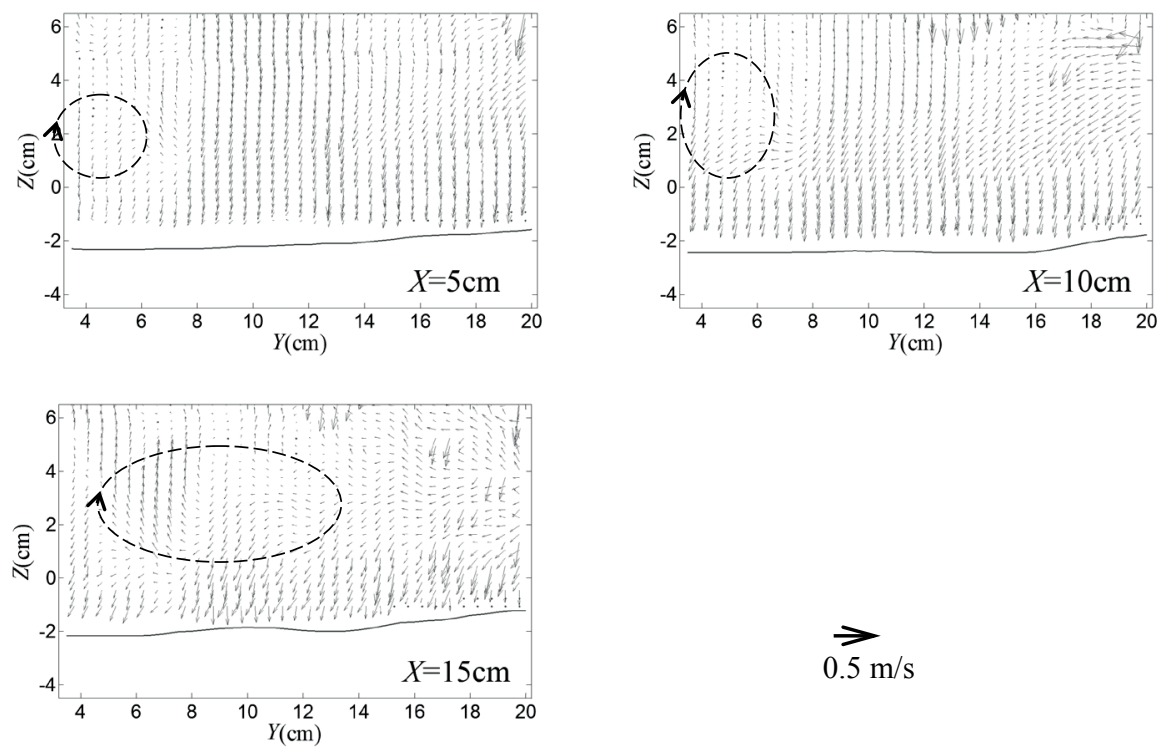

Fig. 5. Vector plots of $V_{t}, \mathrm{NV}$ run. 
very close to the bed and the vectors are oriented towards the rigid-bed channel reach. This behaviour suggests the formation of a recirculation cell near the bed where the maximum scour occurs.

Figure 5 reports the vector plots of the cross-sectional velocity, $V_{t}$, (of intensity $V_{t}=\sqrt{V^{2}+W^{2}}$ ) in the measurement sections where the scour hole develops (i.e. at $X=5, X=10, X=15$ ). Figure 5 shows that a vortex structure develops inside the scour hole near the bed. At $X=10$ this structure tends to move towards the free surface increasing in size. Then, at $X=15$, the structure extends through the whole water depth.

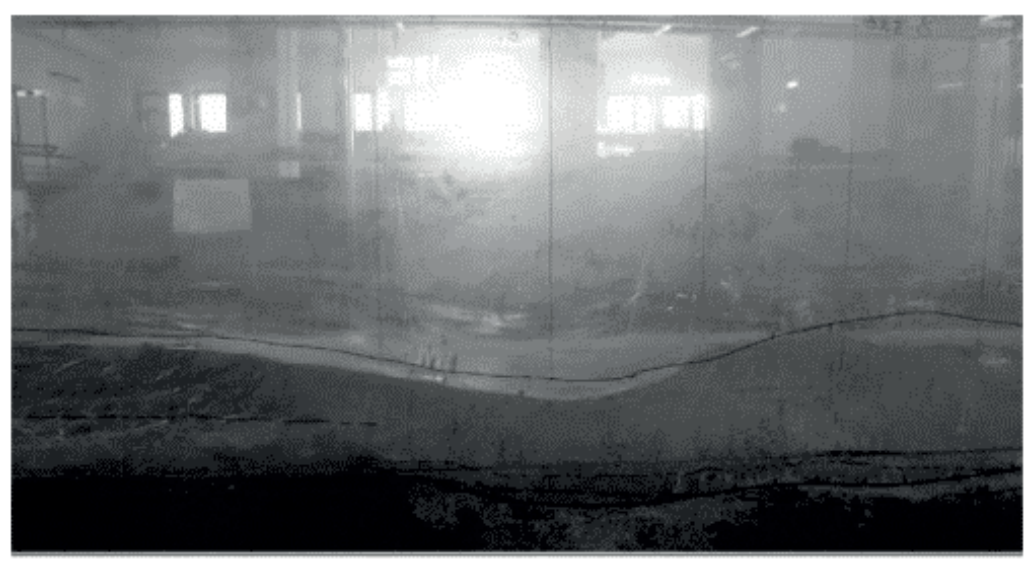

Fig. 6 Photo of the channel reach downstream of the vegetated reach.

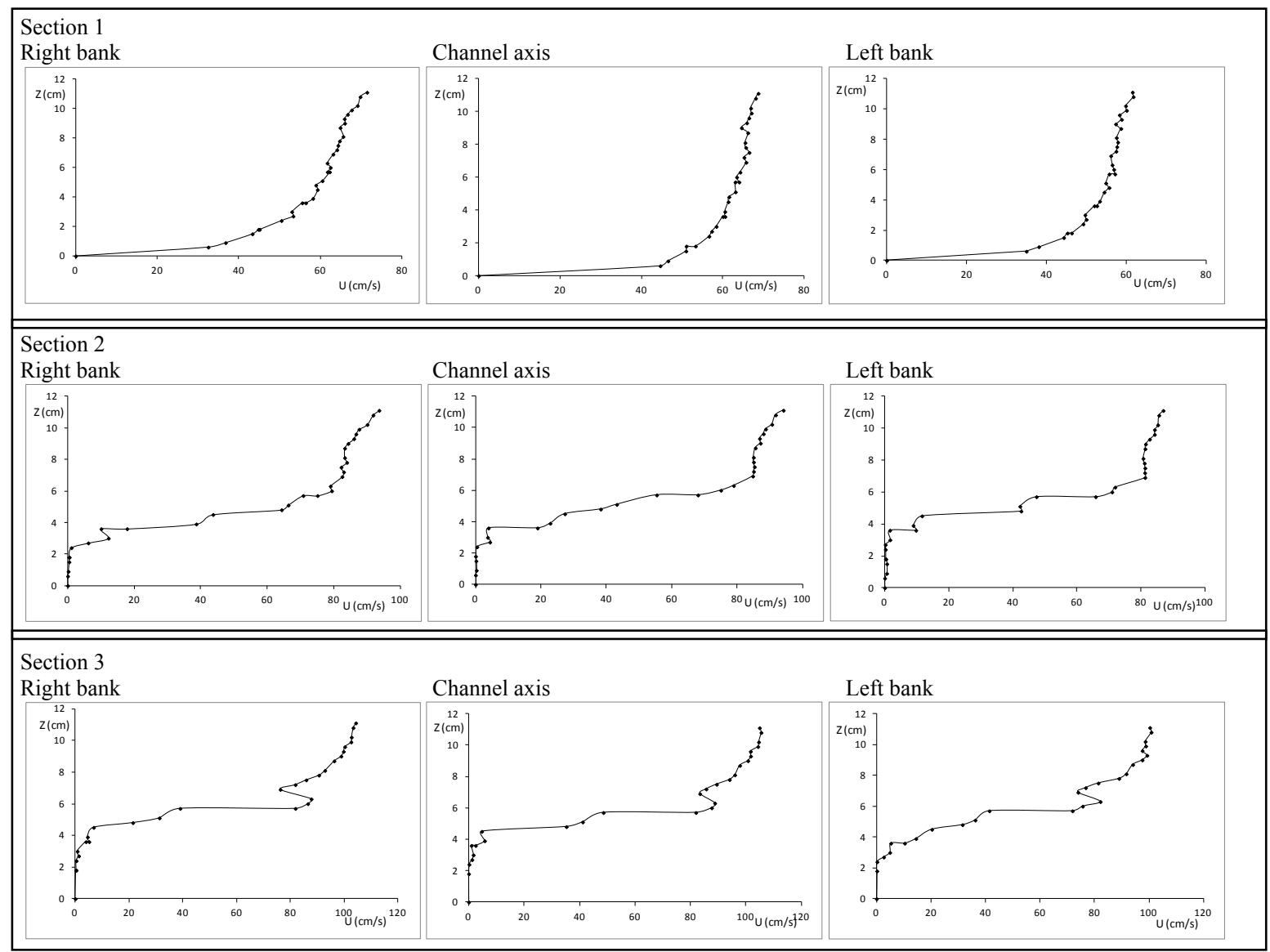

Fig. 7 Vertical profile of the longitudinal velocity - WV run. 
During the WV run, because of the presence of the vegetated reach, the scouring process does not develop downstream of the rigid-bed channel reach. A very slight scour hole appears downstream of the vegetated reach, as shown in Fig. 6.

Figure 7 reports the vertical profiles of the longitudinal flow velocity, $U$, near the banks and at the channel axis in each considered section. From Fig. 7 it can be seen that the presence of vegetation not only causes a decrease of the intensity of the longitudinal velocity component, but it also modifies the shape of the vertical profile. In fact, at the initial section (section 1), a little upstream of the vegetated carpet, the velocity profiles assume the classical shape, that is characterized by increasing values of velocity moving towards the free surface. In the sections downstream, because of the presence of vegetation, the vertical profiles of the longitudinal velocity component are S-shaped, in accordance with other studies conducted in vegetated channels (among others Ghisalberti and Nepft 2002, Carollo et al. 2002, 2005). Thus, very low values of longitudinal velocity occur near the bed and an inflection point is found at approximately the top of vegetated layer.

Figure 8 reports the maps of the transversal velocity $V_{t}$ obtained in sections 1,3 and 5. As Figure 8 shows, the presence of vegetation determines a decrease in the intensity of the transversal flow velocity. The circulation motion is not as evident as that observed in the no-vegetated bed condition.
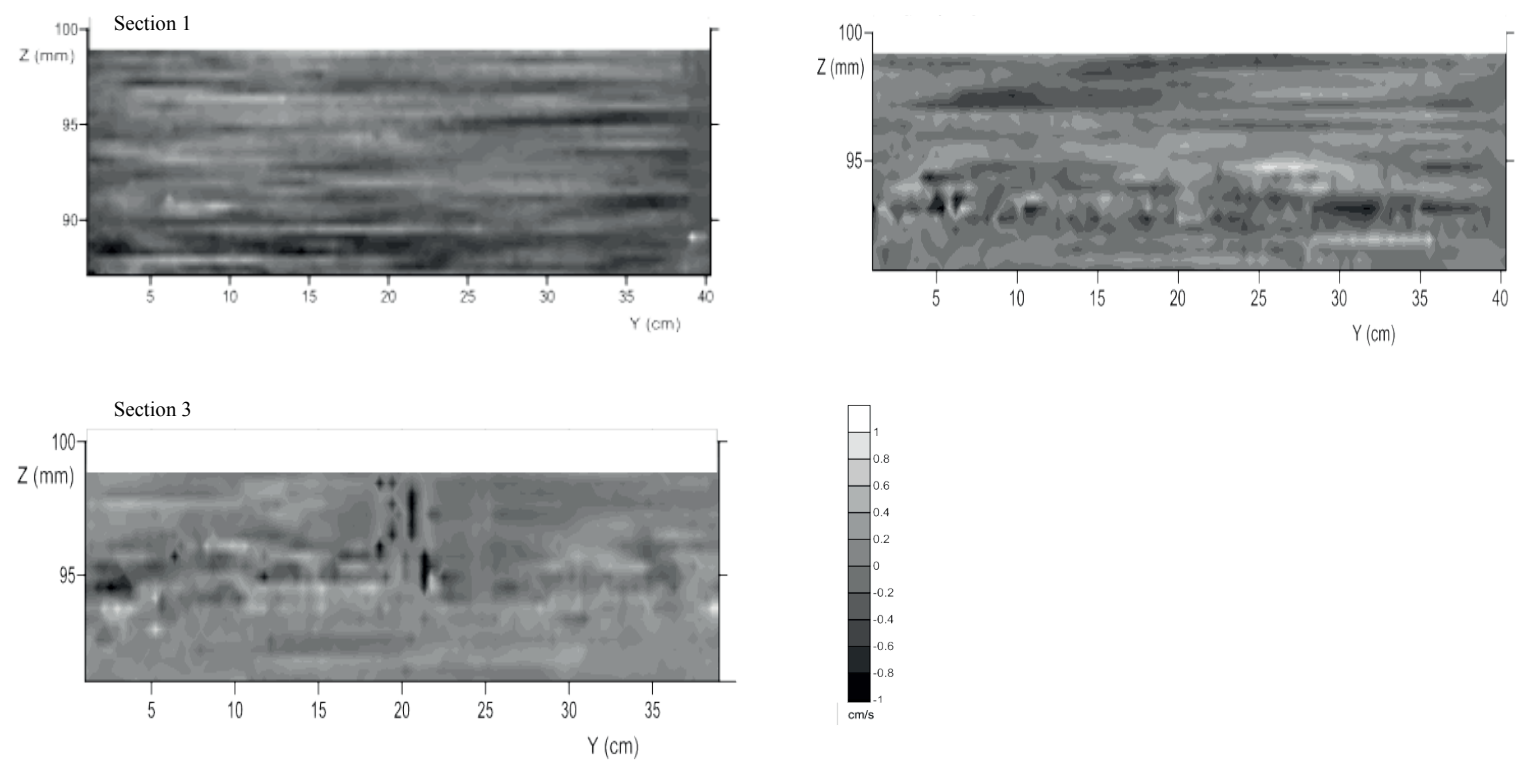

Fig. 8 Transversal velocity - WV run.

\section{CONCLUSION}

In this paper the effects of a vegetated carpet (used as protective measure against local scouring) on the flow velocity field have been investigated. To this aim, instantaneous velocity data in a straight laboratory channel have been collected, downstream of the rigid-bed, over no-vegetated and vegetated beds. In this work particular attention is paid to vegetated bed conditions. In the absence of vegetation it was observed that the scouring process develops downstream of the rigid bed. The scour hole occurs where the gradient of the longitudinal velocity, $U_{l}$, increases and a recirculation cell forms near the bed. In the presence of vegetation, the results obtained show that the excavation does not occur downstream of the rigid-bed reach and only a very slight scour appears downstream of the vegetated reach. Furthermore, because of the presence of vegetation, the vertical profiles of longitudinal velocity assume the typical S-shape so that very low values of longitudinal velocity are obtained near the bed. Also, an effect of the presence of vegetation is that 
the cross-sectional flow motion reduces in comparison with that observed in the no-vegetated bed condition.

Acknowledgements This work was developed within the project "Flow resistance and mixing phenomena in turbulent fluid flows with differently-scaled rough walls" - PRIN2008, co-funded by the Italian Ministry of University and Scientific Research (MIUR) and the University of Palermo.

\section{REFERENCES}

Breusers, H. N. C., Nicollet, G. and Shen, H. W. (1977) Local scour around cylindrical piers. Journal of Hydraulic Research, 15(3), 211-252.

Carollo, F. G., Ferro, V., Termini, D. (2002) Flow velocity measurement in vegetated channels. Journal of Hydraulic Engineering - ASCE, 128(7), 664-673.

Carollo, F. G., Ferro, V., Termini, D. (2005) Flow resistance law in channels with flexible submerged vegetation. Journal of Hydraulic Engineering - ASCE, 131(7), 554-564.

Gaudio, R. and Marion, A. (2003) Time evolution of scouring downstream of bed sills. Journal of Hydraulic Research 41(3), 271-284.

Ghisalberti, M. and Nepf, H. M. (2002). Mixing layer and coherent structures in vegetated acquatic flows. Journal of Geophysical Research 107(2), 3-1-3-11.

Lenzi, M. A. et al. (2002). Local scouring in low and high gradient streams at bed sills. Journal of Hydraulic Research, 40(6), 731-739.

Marion, A., Tregnaghi, M. and Tait, S. (2006). Sediment supply and local scouring at bed sills in high-gradient streams. Water Resources Research, W06416, 42, 11.

Termini, D. and Sammartano, V. (2010). Studio sperimentale del processo di escavazione a valle del fondo rigido di una struttura di controllo: primi risultati”. xxxii convegno di idraulica e costruzioni idrauliche - Palermo (italy) 14-17 settembre 2010; cd-proceedings - ISBN 978-88-903895

Termini, D. and Sammartano, V. (2012). Morphodynamic processes downstream of man-made structural interventions: experimental investigation of the role of turbulent flow structures in the prediction of scour downstream of a rigid bed. Physics and Chemistry of the Earth 49, 18-31. doi.org/10.1016/j.pce.2011.12. 